$09 ; 15$

\title{
Лазерный монитор с независимой подсветкой для наблюдения процессов высокотемпературного горения нанопорошков металлов
}

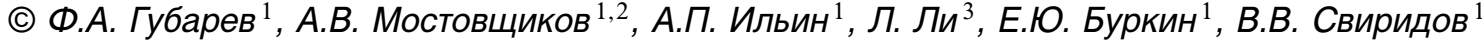 \\ ${ }^{1}$ Томский политехнический университет, Томск, Россия \\ ${ }^{2}$ Томский государственный университет систем управления и радиоэлектроники, Томск, Россия \\ ${ }^{3}$ Liaoning Technical University, Huludao, China \\ E-mail: gubarevfa@tpu.ru
}

Поступило в Редакцию 18 августа 2020г.

В окончательной редакции 9 декабря 2020 г.

Принято к публикации 11 января 2021 г.

Представлен лазерный монитор с независимой подсветкой и зеркальной схемой формирования изображения на основе активной среды на парах бромида меди, позволяющий визуализировать поверхность нанопорошков металлов во время горения. Независимая лазерная подсветка с использованием второго активного элемента на парах бромида меди позволяет значительно повысить контраст изображений по сравнению с контрастом лазерного монитора на основе одного активного элемента, что имеет преимущество при исследовании поверхностей материалов с малым отражением света. Также показана возможность реализации двухканального генератора импульсов для накачки активных элементов на парах бромида меди на основе одного высоковольтного источника питания.

Ключевые слова: лазерный монитор, усилитель яркости, высокотемпературное горение, нанопорошок металла, генератор импульсов.

DOI: 10.21883/PJTF.2021.08.50848.18519

Высокотемпературное горение нано- и микропорошков металлов, в частности нанопорошков алюминия, является одним из основных процессов получения керамических и высокоэнергетических материалов на основе алюминия [1-3]. Температура при горении нанопорошков металлов может превышать $2000 \mathrm{~K}$, и горение может протекать со значительным разлетом продуктов сгорания, что создает сложности при визуальном наблюдении, в том числе с использованием скоростных видеокамер [1-5]. Для исследования процесса горения алюминийсодержащих смесей нанопорошков металлов нашим коллективом были внедрены лазерные мониторы на основе активной среды на парах бромида меди $[4,5]$. Особенностью нанопорошков металлов по сравнению с крупнодисперсными порошками [6,7] является высокая вероятность возгорания под воздействием излучения лазерного монитора. Для дистанционного наблюдения горения нанопорошков нами используется лазерный монитор с зеркальной схемой формирования изображения [5]. Такой лазерный монитор позволяет увеличить область наблюдения, снизив на два порядка плотность мощности освещения (по сравнению с традиционным короткофокусным лазерным монитором). В то же время изображение поверхности формируется темным и менее контрастным [5] при наблюдении поверхности нанопорошков, эффективно поглощающих оптическое излучение.

Авторы работы [8] отмечают преимущества лазерного проекционного микроскопа с независимой подсветкой (по сравнению с традиционным лазерным проекционным микроскопом), заключающиеся в отсутствии ограни- чений, которые накладывает сопряженность подсветки и усиления. Независимая подсветка дает возможность реализации дистанционных схем наблюдения и позволяет варьировать освещенность в зависимости от объекта исследования. Последняя особенность является доминирующим условием при наблюдении объектов, на которые нежелательно воздействовать интенсивным излучением. Такими объектами являются легковоспламеняющиеся нанопорошки металлов, в частности смеси на основе нанопорошков алюминия и железа.

В работах $[7,9]$ сообщается о бистатических лазерных мониторах на основе активных сред на парах бромида меди и их использовании для наблюдения высокотемпературных процессов. В то же время до сих пор в полной мере не реализованы отмеченные в работе [8] преимущества лазерных мониторов с независимой подсветкой (бистатических) перед самосопряженными (моностатическими). В работах [7-9] визуализировались объекты, практически нечувствительные к лазерному излучению мощностью $1-5 \mathrm{~W}$ и обладающие высоким коэффициентом отражения по сравнению с таковым для нанопорошков металлов. В связи с этим целью настоящей работы является разработка лазерного монитора с независимой подсветкой для исследования поверхности нанопорошков металлов во время горения.

Лазерный монитор с независимой подсветкой является системой задающий генератор-усилитель мощности (ЗГ-УМ-система) [10-12]. Задающий генератор в ЗГ-УМ-системе, как правило, строится по схеме с неустойчивым телескопическим резонатором для получения пучка с минимальной расходимостью. Подобная 


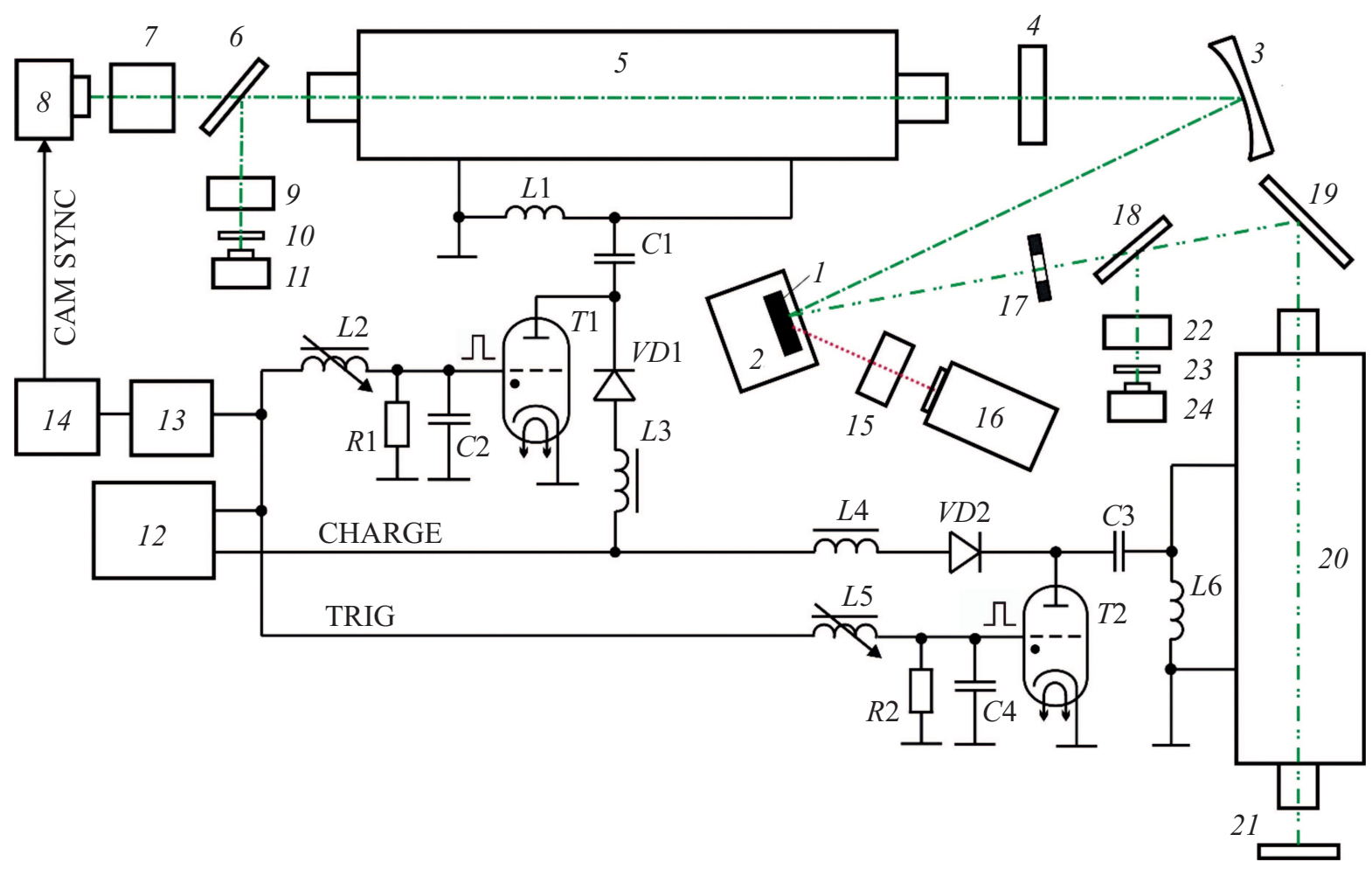

Рис. 1. Схема лазерного монитора с независимой подсветкой. 1 - объект исследования; 2 - предметный столик; 3 - вогнутое зеркало; 4, 9, 15, 22 - линзы; 5 - усилитель яркости; 6 - нейтральный светофильтр/светоделительная пластина; 7 - объектив; 8 - скоростная камера; 10,23 - диффузоры; 11, 24 - фотодиоды; 12 - импульсный источник питания, 13 - оптический преобразователь, 14 - генератор синхроимпульсов, 16 - инициирующий лазер; 17 - диафрагма; 18 - светоделительная пластина; 19, 21 - плоские зеркала; 20 - лазер подсветки; $T 1, T 2$ - тиратроны; $L 1, L 6$ - шунтирующие индуктивности; $L 2, L 5$ - ферровариометры; $L 3, L 4$ - зарядные индуктивности; $C 1, C 3$ - накопительные конденсаторы; $C 2, C 4-$ обостряющие конденсаторы; $R 1, R 2$ - согласующие резисторы; $V D 1, V D 2$ - зарядные диоды.

система использовалась в бистатическом лазерном мониторе в работах [7,9]. Между тем в [7,8] отмечается недостаток бистатической системы, который заключается в появлении лазерных спеклов, искажающих изображение. В настоящей работе мы предлагаем использовать двухпроходовое излучение генератора (с одним зеркалом) с целью уменьшения влияния лазерных спеклов. Кроме того, при использовании двухпроходового излучения достаточно использовать газоразрядную трубку (ГРТ) небольшого активного объема, что позволит упростить и удешевить источник накачки.

Схема лазерного монитора с независимой подсветкой показана на рис. 1. Изображение объекта исследования формировалось схемой, аналогичной использованной в работе [5] и состоящей из вогнутого зеркала с радиусом кривизны $3 \mathrm{~m}$ и собирающей линзы с фокусным расстоянием $1 \mathrm{~m}$. Область наблюдения составляла $6 \mathrm{~mm}$ в диаметре при расстоянии $50 \mathrm{~cm}$ от вогнутого зеркала до объекта. Плотность мощности излучения усилителя яркости в области наблюдения составляла $0.53 \mathrm{~mW} / \mathrm{mm}^{2}$. Усилитель яркости реализован на основе активной среды на парах бромида меди с диаметром $3 \mathrm{~cm}$ и длиной $60 \mathrm{~cm}$ (ГРТ1). Излучение лазера подсветки освещало объект наблюдения через диафрагму диметром $7 \mathrm{~mm}$.
Плотность мощности подсветки в области наблюдения составляла $5.2 \mathrm{~mW} / \mathrm{mm}^{2}$. Лазером подсветки служил $\mathrm{CuBr}$-лазер с диаметром активной области $1.5 \mathrm{~cm}$ и длиной $50 \mathrm{~cm}$ (ГРТ2). ГРТ имели независимый нагрев активной области и контейнеров с рабочим веществом.

Синхронная накачка лазера подсветки и усилителя яркости осуществлялась одним высоковольтным источником питания, реализованным на основе схемы с импульсным зарядом накопительной емкости [13], с двумя тиратронами. Накопительная емкость в разрядном контуре ГРТ1 составляла $1000 \mathrm{pF}$, в разрядном контуре ГРТ2 $680 \mathrm{pF}$. Емкости заряжались до одинакового напряжения $\sim 5.2 \mathrm{kV}$ с частотой $16 \mathrm{kHz}$. Заряд накопительных емкостей осуществлялся от одного двухтактного преобразователя с входным стабилизированным напряжением. Коммутирование накопительных емкостей на ГРТ осуществлялось посредством тиратронов ТГИ1-1000/25. Импульсы запуска тиратронов формировались схемой на основе импульсного трансформатора и подавались на тиратроны через ферровариометры, позволяющие варьировать задержку между импульсами в диапазоне от -50 до $50 \mathrm{~ns}$ с джиттером $\leqslant 2 \mathrm{~ns}$.

Предложенная схемная реализация высоковольтного источника питания и синхронного запуска тиратронов 

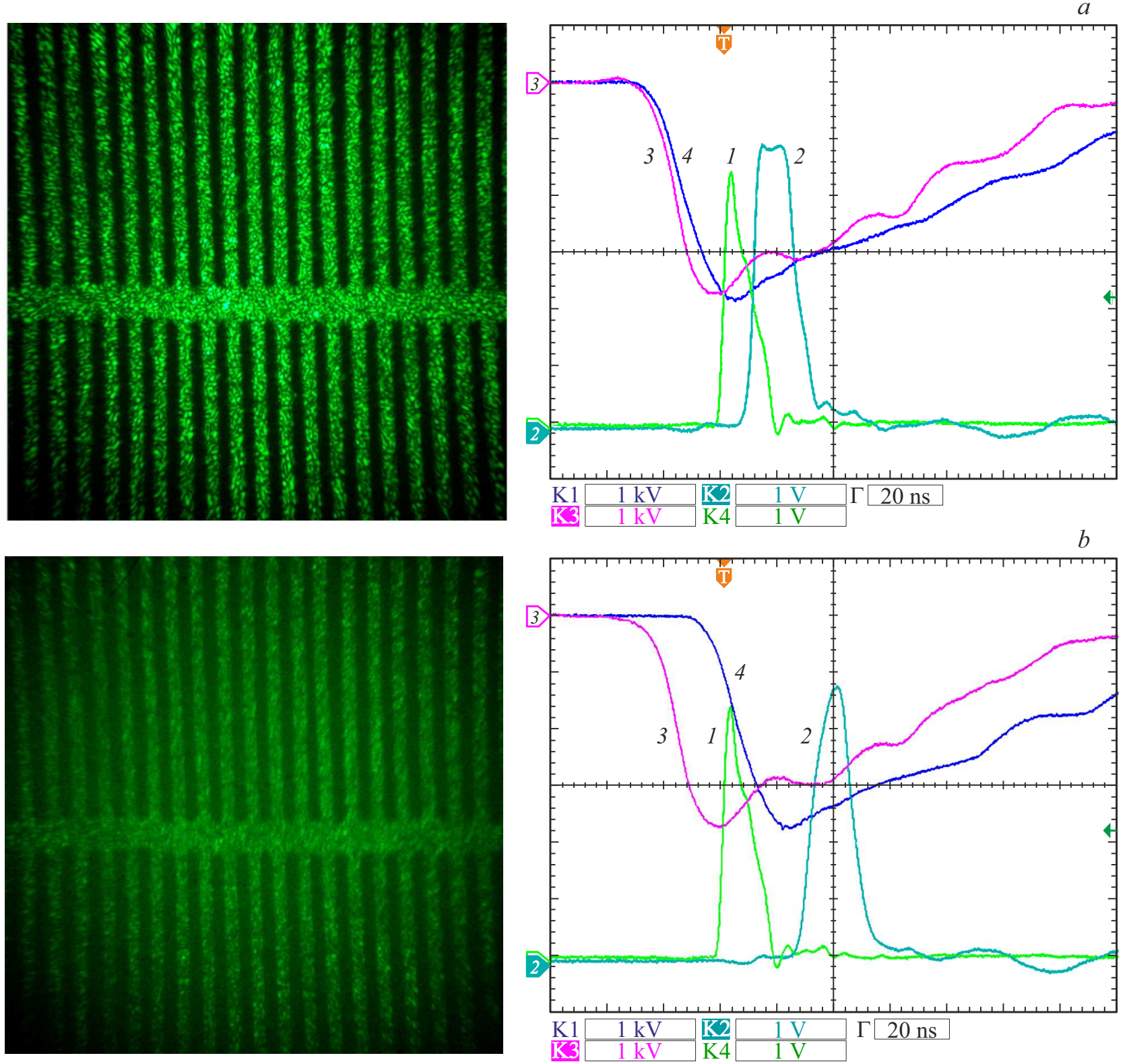

Рис. 2. Изображения тестового объекта, импульсы излучения лазера подсветки (1), усилителя яркости (2), напряжение на ГРТ BA1 (3) и ГРТ ВА2 (4) при согласованной $(a)$ и рассогласованной $(b)$ работе усилителя яркости и лазера подсветки.

позволила упростить, удешевить и сделать более компактной систему накачки. Она имеет два принципиальных отличия от известных в литературе систем синхронизации импульсно-периодического режима работы активных сред на парах металлов: один источник импульсного заряда двух накопительных емкостей и применение одного транзисторного ключа и одного трансформатора в схеме запуска тиратронов. Предложенная в работах [14,15] схема использует два высоковольтных источника питания, т.е. отдельный источник питания для каждого активного элемента; импульсы запуска основных тиратронов формируются схемой на основе дополнительного тиратрона с двумя импульсными трансформаторами.
На рис. 2 показаны изображения тестового объекта медной сетки с шагом $0.3 \mathrm{~mm}$ - при согласованной и рассогласованной работе усилителя яркости и лазера подсветки, а также осциллограммы напряжения на ГРТ и лазерного излучения (осциллограф АКИП-4122/10). Запись изображений осуществлялась скоростной камерой Phantom Miro C110 с разрешением $1024 \times 1024$ рх, скоростью записи $800 \mathrm{fps}$ и установленной экспозицией $5 \mu \mathrm{s}$. Реальная экспозиция в лазерном мониторе равнялась длительности импульса излучения усилителя яркости ( 30 ns). Синхроимпульсы формировались генератором Актаком AWG-4122 с внешней синхронизацией. В диапазоне задержки импульса излучения усилителя яркости по отношению к импульсу излучения лазера подсветки 

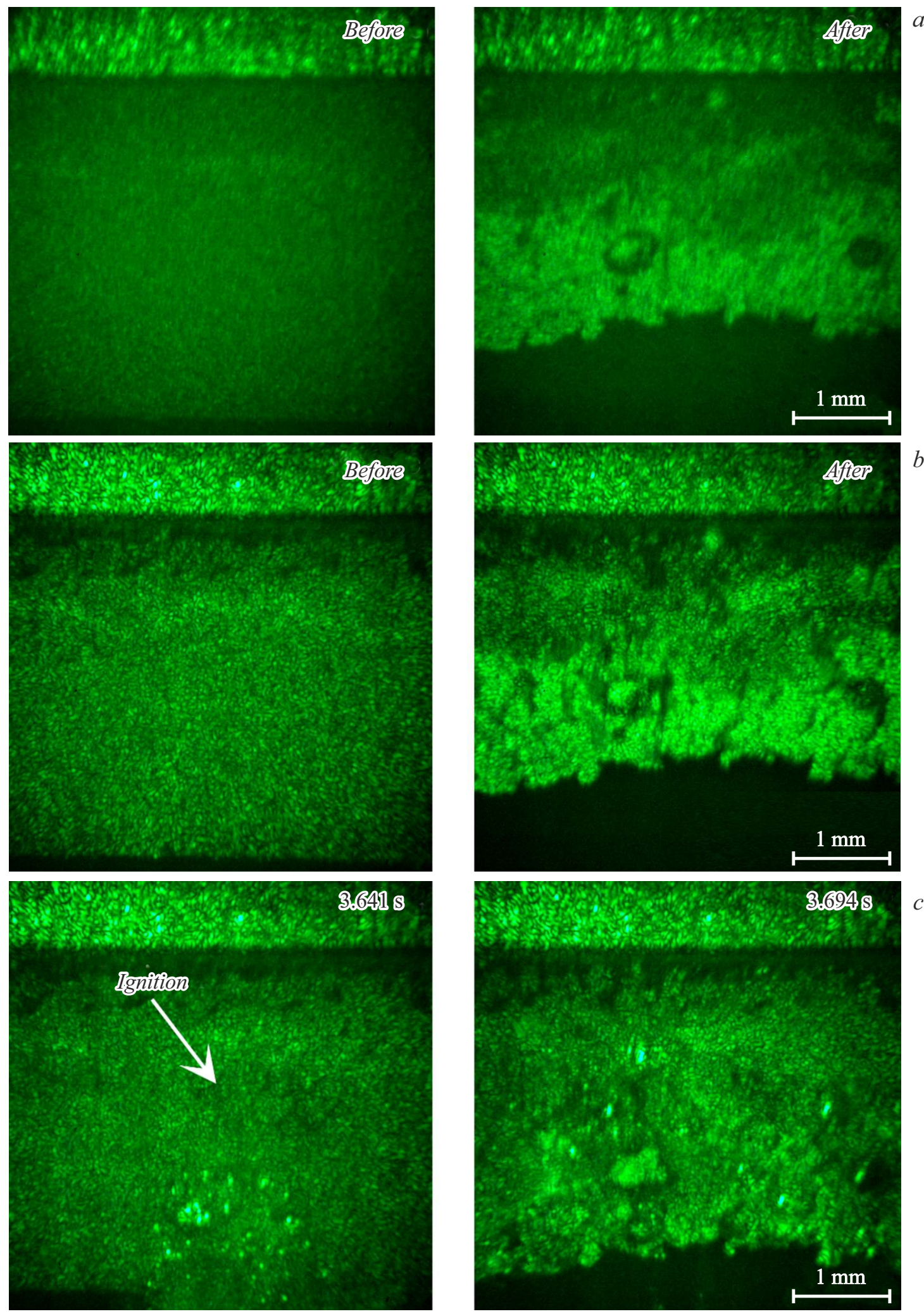

Рис. 3. Изображения поверхности смеси нанопорошков nano-Al-nano-Fe до начала горения/после окончания горения $(a, b)$ и во время горения $(c)$, полученные с использованием лазерного монитора с самосопряженной подсветкой $(a)$ и независимой подсветкой $(b, c)$. Время, указанное на рисунках, отсчитывается от момента включения инициирующего лазера. 
$\Delta t$ от -5 до $20 \mathrm{~ns}$ наблюдались значительное увеличение яркости и повышение контрастности изображений лазерного монитора. Наибольшая яркость изображений соответствовала $\Delta t=10 \mathrm{~ns}$.

С использованием лазерного монитора визуализировалось горение смеси нанопорошков nano-Al-nano-Fe (весовое соотношение 60/40\%). Образец нанопорошка размером $20 \times 5 \times 3 \mathrm{~mm}$ размещался на алюминиевой пластине. Горение инициировалось твердотельным лазером с длиной волны $660 \mathrm{~nm}$ и средней мощностью $2 \mathrm{~W}$. Горение всего образца продолжалось в течение $6.3 \mathrm{~s}$. На рис. 3 показаны изображения поверхности нанопорошка до начала горения и после окончания горения, полученные с использованием традиционного и бистатического лазерных мониторов, а также изображения во время горения. Как следует из результатов визуализации, использование независимой подсветки позволяет существенно повысить контраст изображений поверхности с малым коэффициентом отражения, в частности поверхности нанопорошков металлов.

Таким образом, в работе впервые показана возможность использования бистатического лазерного монитора для наблюдения поверхности нанопорошков металлов во время горения. Применение двухпроходового излучения активной среды в качестве излучения подсветки позволяет существенно упростить оптическую схему бистатического лазерного монитора, снизить интенсивность подсветки и использовать один источник питания для заряда рабочих емкостей лазера подсветки и усилителя яркости.

\section{Конфликт интересов}

Авторы заявляют, что у них нет конфликта интересов.

\section{Список литературы}

[1] V.E. Zarko, A.A. Gromov, Energetic nanomaterials: synthesis, characterization, and application (Elsevier, 2016). DOI: 10.1016/C2014-0-01661-9

[2] А.А.Громов, Т.А. Хабас, А.П. Ильин, Е.М. Попенко, А.Г. Коротких, В.А. Архипов, А.А. Дитц, Ю.И. Строкова, Л.О. Толбанова, Горение нанопорошков металлов (Дельтаплан, Томск, 2008).

[3] Д. Сандарам, В. Янг, В.Е. Зарко, Физика горения и взрыва, 51 (2), 37 (2015). [Пер. версия: 10.1134/S0010508215020045].

[4] L. Li, A.V. Mostovshchikov, A.P. Ilyin, A. Smirnov, F.A. Gubarev, IEEE Trans. Instrum. Meas., 69 (2), 457 (2020). DOI: 10.1109/TIM.2019.2903616

[5] L. Li, A.V. Mostovshchikov, A.P. Ilyin, P.A. Antipov, D.V. Shiyanov, F.A. Gubarev, J. Appl. Phys., 127 (19), 194503 (2020). DOI: $10.1063 / 1.5139508$

[6] G.S. Evtushenko, M.V. Trigub, F.A. Gubarev, T.G. Evtushenko, S.N. Torgaev, D.V. Shiyanov, Rev. Sci. Instrum., 85 (3), 03311 (2014). DOI: 10.1063/1.4869155

[7] M.V. Trigub, N.A. Vasnev, G.S. Evtushenko, Appl. Phys. B, 126 (3), 33 (2020). DOI: 10.1007/s00340-020-7387-5
[8] В.К. Исаков, М.М. Калугин, Е.Н. Парфенова, С.Е. Потапов, ЖТФ, 53 (4), 704 (1983).

[9] М.В. Тригуб, С.Н. Торгаев, Г.С. Евтушенко, В.О. Троицкий, Д.В. Шиянов, Письма в ЖТФ, 42 (12), 51 (2016). [Пер. версия: 10.1134/S1063785016060298].

[10] А.Г. Григорьянц, М.А. Казарян, Н.А. Лябин, Лазеры на парах меди: конструкция, характеристики и применения (Физматлит, М., 2005).

[11] D.N. Astadjov, L.I. Stoychev, S.K. Dixit, S.V. Nakhe, N.V. Sabotinov, IEEE J. Quant. Electron., 41 (8), 1097 (2005). DOI: 10.1109/JQE.2005.850701

[12] F.A. Gubarev, V.O. Troitskiy, M.V. Trigub, V.B. Sukhanov, Opt. Commun., 284 (10-11), 2565 (2011). DOI: $10.1016 /$ j.optcom.2011.01.047

[13] Е.Ю. Буркин, О.А. Кожемяк, Приборы и техника эксперимента, № 2, 91 (2016). [Пер. версия: 10.1134/S0020441216010292].

[14] М.В. Тригуб, Н.А. Васнев, Г.С. Евтушенко, В.А. Димаки, Приборы и техника эксперимента, № 1, 30 (2019). [Пер. версия: 10.1134/S0020441218060258].

[15] Н.А. Васнев, М.В. Тригуб, В.А. Димаки, Г.С. Евтушенко, В.О. Троицкий, В.В. Власов, Патент на полезную модель № 185671 (Дата регистрации 13.12.2018). 